parental blood pressure has been measured. ${ }^{3}$ It is interesting, however, that the relation between birth weight, maternal age, and birth rank and blood pressure were largely unaffected by adjustment for reported parental history of high blood pressure and seemed to be similar in children with and without a maternal history of hypertension. These findings suggest that the means by which familial influences on blood pressure are mediated are quite separate from those of the other factors discussed.

The study was supported by a project grant from the Medical Research Council. We thank the education authorities, schools, parents, and children for their cooperation and interest; Tenovus Cancer Charity for use of facilities; and Catherine Bond, Dave Macfarlane, Madeleine St Clair, and Mary Walker for their contributions.

1 de Swiet $M$, Fayers $P$, Shinebourne EA. Blood pressure survey in a population of normal infants. Br Med $\mathcal{J}$ 1976;ii:9-11.

2 Levine RS, Hennekens CH, Klein B, et al. Tracking correlations of blood pressure levels in infancy. Pediatrics 1978;61:121-5.

Zinner SH, Levy PS, Kass EH. Familial aggregation of blood pressure in childhood. N Engl f Med 1971:284:401-4

4 Prior IAM, Grimley Evans J, Harvey HPB, et al. Sodium intake and blood pressure in two Polynesian populations. N Engl f Med 1968;279:515-20.

5 Whincup PH, Cook DG, Shaper AG, Macfarlane DJ, Walker M. Blood pressure in British children: associations with adult blood pressure and cardiovascular mortality: Lancet 1988: ii:890-3.

6 Beaglehole R, Eyles E, Salmond C, Prior I. Blood pressure in Tokelaun children in two contrasting environments. Am f Epidemiol 1978; 108:179-86.

7 Hofman A, Hazebroek A, Valkenburg HA. A randomised trial of sodium intake and blood pressure in newborn infants. FAMA 1983;250:370-3.

8 Barker DJP, Osmond C. Death rates from stroke in England and Wales predicted from past maternal mortality. Br.Med F 1987;295:83-6.

9 Wadsworth MEJ, Cripps HA, Midwinter RE, Colley JRT. Blood pressure in a national birth cohort at the age of 36 related to social and familial factors, smoking, and body mass. Br.Med J 1985;291:1534-8.

10 Barker DJP, Osmond C, Golding J, Kuh D, Wadsworth MEJ. Growth in utero, blood pressure in childhood and adult life, and mortality from cardiovascular disease. Br Med 7 1989.298:564-7.

11 Ounsted MK, Cockburn JM, Moar VA, Redman CWG. Factors associated with the blood pressures of children born to women who were hypertensive during pregnancy. Arch Dis Child 1985;60:631-5.

12 Shaper AG, Ashby D, Pocock SJ. Blood pressure and hypertension in middle-aged British men. I Hypertens $19 \overline{8} ; 6 ; 6: 367-74$
13 Prineas RJ, Gillum RF, Hirobe H, Hannan PJ. The Minneapolis children's blood pressure study Part 1: standards of measurement for children's blood pressure. Hypertension 1980;2 (suppl 1):18-24.

14 Whincup PH, Cook DG, Shaper AG. Blood pressure measurement in children; the importance of cuff size. $\mathcal{f}$ Hypertens (in press).

15 Eaton-Evans J, Dugdale AE. Recall by mothers of birth weights and feeding of their children. Human Nutrition: Applied Nutrition 1986;40A:171-5.

16 Office of Population Censuses and Surveys. Occupational mortality: childhood supplement. The registrar general's decennial supplement for England and Wales 1979-80, 1982-3. Series DS 8. London: HMSO, 1988.

17 Simpson A, Mortimer JG, Silva PA, Spears G, Williams S. Correlates of blood pressure in a cohort of Dunedin seven year old children. In: Onesti G, Kim $\mathrm{KE}$, eds. Hypertension in the voung and old. New York: Grune and Stratton, 1981:153-63.

18 Cater J, Gill $M$. The follow-up study: medical aspects. In: Illsey R, Mitchell $\mathrm{RG}$, eds. Low birth weight, a medical psychological and social study. Chichester: Wiley, 1984:191-205.

19 Gennser G, Rymark P, Isberg PE. Low birth weight and risk of high blood pressure in adulthood. Br Med f 1988;296:1498-1500

20 Lee Y-H, Rosner B, Gould JB, Lowe EW, Kass EH. Familial aggregation of blood pressures of newborn infants and their mothers. Pediatrics 1976;58 $722-9$.

21 Kitterman JA, Phibbs RH, Tooley WH. Aortic blood pressure in normal newborn infants during the first 12 hours of life. Pediatrics 1969;44:959-68

22 Schachter J, Kuller LH, Perkins JM, Radin ME. Infant blood pressure an heart rate: relation to ethnic group (black or white), nutrition and electrolyte intake. Am f Epidemiol 1979:110:205-18.

23 Bucci (i, Scalamandre A, Savignoni PG, et al. The systemic systolic blox pressure of newhorns with low weight. Acta Paediutr Scand [Suppl] 1972;229:1-26.

24 Holland WW, Young IM. Neonatal blood pressure in relation to maturity, mode of delivery, and condition at bith. Br Med $\mathcal{J}$ 1956;ii:1331-3.

25 Versmold HT, Kitterman JA, Phibbs RH, Gregory GA, Tooley WH. Aortic blood pressures during the first 12 hours of life in infants with birthweight 610 to +220 grams. Pediatrics 1981;67:607-13.

26 Thomson J. Observations on weight gain in infants. Arch Dis Child 1955:30 $322-7$

27 Cruise MO. A longitudinal study of the growth of low birthweight infants. Pediatrics 1973:51:620-8

28 Werner B. Fertility trends in the UK and in thirteen other developed countries, 1966-1986. Population Trends 1988;51:18-24.

29 Office of Population Censuses and Surveys Population Statistics Division. Live births in 1987. Population Trends 1988;53:35-40.

30 Paul AA, Southgate DAT. McCance and Widdowson's The composition of foods. thed. London: HMSO, 1978

31 Marmot MG, Page CM, Atkins E, Douglas JWB. Effect of breast-feeding on plasma cholesterol and weight in young adults. $\mathcal{f}$ Epidemiol Community Health 1980;34:16+-7.

32 Lucas A, Morley R, Hudson GJ, et al. Early sodium intake and later blood pressure in preterm infants. Arch Dis Child 1988;63:656-7.

(Accepted 26 June 1989)
Eastern Health and Social Services Board, Belfast Anthony B Stevens, MRCP, senior registrar

Diabetic Clinic, Royal Victoria Hospital, Belfast Michael Roberts, MRCP, senior house officer Albert B Atkinson, FRCP, consultant physician Patrick M Bell, FRCP consultant physician

Diabetic Clinic, Belfast City Hospital, Belfast Roland McKane, MRCP, senior house officer J Randal Hayes, FRCP, consultant physician

Correspondence and requests for reprints to: Dr A Stevens, Occupationa Health Service, 91 Lisburn Road, Belfast BT9 7AE.

BrMed f 1989;299:591-5

\title{
Motor vehicle driving among diabetics taking insulin and non-diabetics
}

\author{
Anthony B Stevens, Michael Roberts, Roland McKane, Albert B Atkinson, Patrick M Bell, \\ J Randal Hayes
}

\section{Abstract}

Objective-To determine whether rates of road traffic accidents were higher in diabetics treated with insulin than in non-diabetic subjects.

Design-Controlled, five year retrospective survey.

Setting-Diabetic, dermatology, and gastroenterology outpatient clinics.

Patients -596 Diabetics treated with insulin (354 drivers) aged 18-65 attending two clinics and 476 non-diabetic outpatients ( 302 drivers).

Main outcome measures-Rates of accidents in diabetic and non-diabetic subjects.

Results-A self completed questionnaire was used to record age, sex, driving state, and rates of accidents and convictions for motoring offences among diabetic and non-diabetic volunteers. For the diabetic volunteers further information was obtained on treatment, experience of hypoglycaemia, and declaration of disability to the Driving and Vehicle Licensing Centre and their insurance company. Accident rates were similar $(81(23 \%)$ diabetic and 76 (25\%) non-diabetic drivers had had accidents in the previous five years). A total of 103 diabetic drivers had recognised hypoglycaemic symptoms while driving during the previous year. Only 12 reported that hypoglycaemia had ever caused an accident. Overall, 249 had declared their diabetes to an insurance company. Of these, 107 had been required to pay an increased premium, but there was no excess of accidents in this group.

Conclusions-Diabetic drivers treated with insulin and attending clinics have no more accidents than non-diabetic subjects and may be penalised unfairly by insurance companies.

\section{Introduction}

Diabetes mellitus in drivers of motor vehicles is assumed to be a potential danger both to the driver and to other road users. This belief stems from both the immediate disabling effects of hypoglycaemia and the long term implications of the disease, particularly retinopathy. With these problems diabetics might be expected to have more road traffic accidents than the general population, but available evidence is conflicting. Early studies from the United States have consistently shown higher accident rates for diabetic 
motorists, ${ }^{1-3}$ but Ysander's work showed reduced rates among Swedish diabetic drivers. ${ }^{4}$ We could not find a comparable controlled study in the United Kingdom, but recent evidence has suggested that insulin dependent diabetic drivers have no excess of accidents. ${ }^{5}$

We compared rates of road traffic accidents among diabetic drivers taking insulin and non-diabetic drivers. We also assessed the motoring practices of diabetic drivers and the attitudes of insurance companies towards them.

\section{Subjects and methods}

A complete census of insulin dependent and noninsulin dependent diabetic patients, aged 18-65 inclusive on 1 October 1986, who had been taking insulin for at least one year was carried out at two diabetic clinics in Belfast. During an initial period of four months individual patients were recruited when they attended their respective clinic. A further eight months' follow up was required to recruit subjects who did not attend in the initial four months. Patients gave informed oral consent before participating in the survey, which had been approved by the ethical committee of Queen's University, Belfast. Each volunteer completed a confidential questionnaire under supervision by one of us.

The questionnaire was divided into three sections. In the first section personal and clinical details were recorded by the supervisor. The second and third sections contained multiple choice questions and questions requiring simple yes/no answers. Some questions also required subjects to give brief written details. The second section asked for information on home monitoring of blood glucose concentration, experience of hypoglycaemia, and alcohol consumption. In the third section the current driving state of patients was established. All patients who at the time of the survey drove motor vehicles on public roads were asked for details of their driving experience. The numbers of accidents and driving convictions since starting insulin treatment, and becoming a motorist or during the past five years, whichever was the shorter, were recorded. An accident was defined as any road traffic accident that resulted in injury, a vehicle requiring repairs in a garage, or an insurance claim, or any combination. All such accidents in which the subject was the driver, whether or not he or she was at fault, were included. Patients were asked about their experience with hypoglycaemia while driving. They were asked whether they had declared their condition to the Driving and Vehicle Licensing Centre and their insurance company. Information was then sought on the attitudes of insurance companies to diabetic drivers. Finally, each diabetic driver was assessed on knowledge of the relevant legislation and the recommendations of the British Diabetic Association for drivers. Visual acuity was measured by using a Snellen chart with the subject wearing spectacles if these were normally worn for driving.

A similar questionnaire was completed by a control group recruited from a gastroenterology clinic and a dermatology clinic. The questions on driving experience, accidents, convictions, and alcohol consumption were identical with those in the questionnaire for diabetics. The same definition of an accident was used. All patients aged 18-65 attending these clinics during a period of four months who did not have diabetes mellitus were asked to volunteer. Each volunteer gave informed oral consent before filling in a questionnaire and having visual acuity tested with a Snellen chart.

Contingency tables were obtained with the statistical package for social sciences (SPSS) and analysed by using $\chi^{2}$ tests. When we were concerned that certain variables might introduce bias into the comparison of diabetic and non-diabetic groups we undertook stratified analyses by using Cochran's method. ${ }^{6}$

\section{Results}

A total of 596 diabetic patients (298 men, 298 women; mean (SD) age 43 (14) years) completed questionnaires. This represented $92 \%$ of the total population who met the criteria for inclusion. Of the 49 who did not participate, three were out of the country, three refused to complete questionnaires, one died before participation, and the remainder were infrequent attenders at the clinics whom we failed to recruit. The non-participants were similar in age, sex, duration of diabetes, and glycated haemoglobin concentration to the participants. All 476 non-diabetic outpatients who were asked to participate agreed (236 men, 240 women; mean age 40 (14) years). The numbers of diabetics and non-diabetics who were current drivers of motor vehicles on public roads were similar $(354(59 \%) v 302(63 \%))$. The two groups of drivers were well matched for sex ( 217 men, 137 women $v 175$ men, 127 women, respectively), but diabetic drivers were older (mean age 41 (13) years $v 37$ (13) years). Table I shows that diabetic drivers had held driving licences for longer and that alcohol consumption was greater among non-diabetic drivers. The table

TABLE I-Details on driving and alcohol consumption for diabetics taking insulin and non-diabetics. Figures are numbers (percentages) of subjects

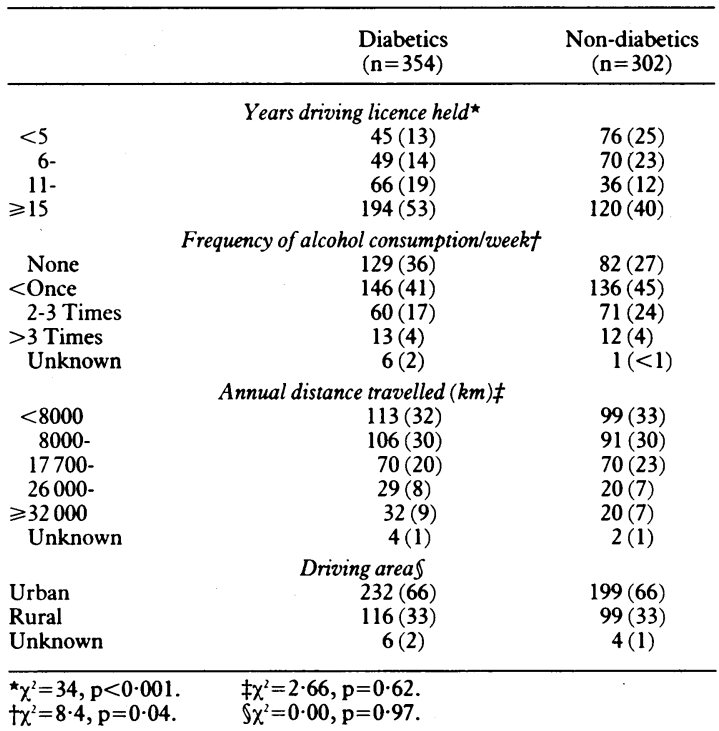

also shows that the distribution of other variables (annual distance driven and usual driving area) was similar in the two groups.

Fifty $(8 \cdot 4 \%)$ diabetics who were non-drivers at the time of the survey had been drivers in the past. Fifteen of these had stopped driving for reasons directly associated with diabetes mellitus: five because of retinopathy and inadequate visual acuity, six because of hypoglycaemia, and four simply because they had diabetes. Five others had stopped driving as a result of peripheral or cardiovascular disease. Three diabetic drivers had given up for medical reasons unrelated to diabetes. Forty nine $(10 \cdot 3 \%)$ non-diabetic subjects had been drivers in the past, seven having given up for medical reasons.

Accidents and motoring offences-The numbers of drivers from each group reporting accidents was not significantly different. Eighty two $(23 \cdot 2 \%)$ diabetic drivers and $75(24.8 \%)$ non-diabetic drivers had had one or more accidents during the five years (table II). Analysis with Cochran's method stratified for age and 


\begin{tabular}{|c|c|c|c|c|c|c|}
\hline & $\begin{array}{l}\text { Diabetics } \\
(\mathrm{n}=354)\end{array}$ & $\begin{array}{l}\text { Non-diabetics } \\
(\mathrm{n}=302)\end{array}$ & $\begin{array}{l}\text { Difference } \\
(\%)\end{array}$ & $\begin{array}{c}95 \% \\
\text { Confidence } \\
\text { interval of } \\
\text { difference }\end{array}$ & $\chi^{2}$ & $\mathrm{p}$ Value \\
\hline $\begin{array}{l}\text { Basic data } \\
\text { Stratified for: }\end{array}$ & $82(23 \cdot 2 \%)$ & $75(24 \cdot 8 \%)$ & $-1 \cdot 7^{\star}$ & $-8 \cdot 3$ to $4 \cdot 9$ & 0.25 & 0.62 \\
\hline $\begin{array}{l}\text { Age and sex } \\
\text { Duration driving licence held }\end{array}$ & & & $\begin{array}{l}-1 \cdot 6 \\
-1 \cdot 5\end{array}$ & $\begin{array}{l}-8 \cdot 2 \text { to } 5 \cdot 0 \\
-8 \cdot 3 \text { to } 5 \cdot 3\end{array}$ & $\begin{array}{l}0 \cdot 23 \\
0 \cdot 19\end{array}$ & $\begin{array}{l}0.63 \\
0 \cdot 66\end{array}$ \\
\hline Alcohol consumption & & & $-1 \cdot 6$ & $-8 \cdot 2$ to $5 \cdot 0$ & $0 \cdot 23$ & 0.63 \\
\hline
\end{tabular}

${ }^{\star} \mathrm{A}$ rounding error exists. centre, but only 207 considered that this declaration was compulsory. Two hundred and forty nine drivers had declared their condition to their present insurance company. Of the 17 drivers with visual acuity of $6 / 12$ or worse, five had declared their condition to the licensing centre. Nine had declared their condition to insurance companies, but only three of them had been required to provide a medical report. Two hundred and seventy eight drivers knew that driving while hypoglycaemic was an offence under the law, and 236 thought that insulin was a drug. One hundred and sixty three thought that driving heavy goods vehicles was prohibited. In the event of suffering hypoglycaemic symptoms while driving 286 drivers said that they would stop immediately and take glucose in some form. Seventy nine stated that they would also vacate the driving seat. Thirty five drivers said that they would take glucose but keep driving, while a further 24 said that they would either drive home carefully or drive to a cafe or shop. Two hundred and ninety four drivers permanently carried a supply of glucose or an equivalent in their car.

Attitudes of insurance companies to diabetic driversTwenty drivers had been refused motor insurance for reasons attributed to diabetes. This refusal followed a medical report from the driver's diabetic specialist or general practitioner in only two cases. Four others had been refused insurance for reasons unconnected with diabetes. All had subsequently obtained insurance, but one had failed to declare diabetes to the new company. Of eight non-diabetic drivers who had been refused insurance, only one stated that this was as a result of a medical condition. One hundred and seven diabetic drivers had had to pay increased premiums when they declared their diabetes to the motor insurance company. Of these drivers, 24 had not been required to provide a medical report. The group paying increased premiums had not had any more accidents than the group paying unchanged premiums (25 (23\%) with accidents $v 36(27 \%))$. Comparison of previous experience of severe hypoglycaemia, presence of warning symptoms of hypoglycaemia, alcohol use, and frequency of self monitoring of blood glucose concentrations showed no difference between the two groups. There were insufficient motoring convictions to include this variable in the analysis. (1) drivers had had an accident. Of the diabetic motorists treated with insulin, 86 were taking drugs for conditions other than diabetes mellitus. Twenty one $(24 \cdot 3 \%)$ of this subgroup had had accidents compared with 61 $(22 \cdot 8 \%)$ of drivers treated with insulin alone.

Hypoglycaemia among diabetic drivers - A total of 101 diabetic drivers admitted to having suffered symptoms that they recognised as indicating hypoglycaemia while driving during the preceding year. Forty six of these drivers reported that such an event had happened two to five times during the year, and 13 reported that it had happened more than five times. The number of hypoglycaemic episodes while driving during the past year was associated with the total number of accidents experienced by drivers during the five years (table IV). Drivers were asked whether a hypoglycaemic attack had ever caused them to have an accident during their entire driving career. Twelve $(3 \%)$ had had such an event, 11 once and one twice.

Attitudes, knowledge, and practices of diabetic drivers-Three diabetic men taking insulin held licences to drive heavy goods vehicles. None of them had declared their condition to the Driving and Vehicle Licensing Centre. Five others drove lorries but did not hold heavy goods vehicle licences. One diabetic described himself as a crane driver and another used an earth mover. Two drivers held licences to drive public service vehicles, neither having declared their diabetes to the licensing centre. Two hundred and thirty four drivers had declared their diabetes to the licensing

\section{Discussion}

We compared a sample of diabetic outpatients taking insulin with non-diabetic medical outpatients and found no significant difference in the number of current drivers in each group or in distance driven annually. There were no more road traffic accidents or convictions for motoring offences among diabetic drivers taking insulin even when differences in age, sex, driving experience, and alcohol consumption were taken into account. We know of no other controlled study in the United Kingdom, though a recent investigation from Scotland, ${ }^{5}$ in which Eadington and Frier reviewed the driving experiences of insulin dependent diabetic drivers, produced an overall accident rate similar to that found by us. In the Scottish study comparison was made with data from the Department of Transport and insurance companies, giving accident rates for the general population; the rates for insulin dependent diabetic drivers were no higher. In a recent case-control study by Songer $e t a l$ in the United States there were no more accidents among insulin treated diabetic drivers than in the general population. ${ }^{7}$ It is important to point out that in the present study and that of Eadington and Frier the diabetic drivers were a selected group. Those who had diabetic complications or difficulties with hypoglycaemia had often stopped driving, and this may have contributed to the good
*Information on 11 drivers was $\chi^{2}=7 \cdot 07, p=0.03$ 
accident record. Interestingly, both Eadington and Frier and Songer $e t$ al found that most diabetics who stopped driving did so voluntarily rather than as a consequence of revocation of their driving licence.

Although our results suggest that diabetics taking insulin are safe drivers, the risks of hypoglycaemia must still be recognised. Two previous studies in the United Kingdom have investigated the frequency of hypoglycaemia while driving. Clarke $e t$ al found that $40 \%$ of insulin dependent drivers suffered such an event. ${ }^{8}$ Eadington and Frier reported that 34 out of a total of 166 insulin dependent drivers admitted to one or more episodes of hypoglycaemia while driving during an eight year period. These results compare with our finding that $29 \%$ (103) had been hypoglycaemic while driving over the previous year. In common with Eadington and Frier we found a significant increase in accidents among these drivers.

The serious consequences of insulin induced hypoglycaemia are illustrated by reports of accidents and dangerous driving. ${ }^{9-12}$ Data from the Department of Transport on 2000 accidents reported to the police which were caused by collapse at the wheel showed that $17 \%$ resulted from hypoglycaemia (Dr J F Taylor, personal communication). Previous reports, however, indicate that such events are infrequent. ${ }^{413-15}$ Only 12 of our drivers admitted that an accident had ever been caused by hypoglycaemia. In Eadington and Frier's study nine accidents were attributed to hypoglycaemia, though these represented a substantial proportion $(16 \%)$ of the total number of accidents recorded Overall, these findings are reassuring, though patients may underreport such events for fear of losing their licences.

A substantial number of drivers failed to notify the Driving and Vehicle Licensing Centre of their diabetes As observed elsewhere, ${ }^{16}$ more drivers declared their diabetes to the insurance company, though, ironically, third party insurance may be rendered invalid if the driver has not informed the licensing centre of the diabetes. The fear of failing to obtain a licence or insurance cover or of paying increased premiums is likely to deter diabetics from declaring their condition. Inconsistent decisions by insurance companies on cover and premiums made without medical reports may well encourage this.

The Road Traffic Acts 1988 require a licence holder to notify the secretary of state (in practice the licensing centre) of any disability that he or she has reason to believe will last more than three months. Such disabilities may be relevant or prospective, and diabetes may come into either of these categories, whatever its method of treatment. This advice appears on every driving licence. On receiving notification of diabetes the medical branch of the licensing centre assesses fitness to drive by using a questionnaire and with the advice of the applicant's diabetic specialist if considered necessary. Licences are then issued for one, two, or three years or in some cases revoked or refused. Failure to notify the authorities of a relevant or prospective disability is a criminal offence, punishable by a fine of up to $£ 400$ (Road Traffic Acts 1988).

We identified both diabetic and non-diabetic drivers with inadequate visual acuity by using a Snellen chart. The chart does not accurately mimic the standard eye test for number plates, but a corrected visual acuity of $6 / 12+2$ is taken as about equal to the minimum required. ${ }^{17}$ Among the diabetic drivers with poor vision most had failed to declare their diabetes to the licensing centre, thereby missing medical scrutiny. Although more diabetic drivers had informed their insurance company of their diabetes, the same companies failed to detect those with poor vision as they often did not require a medical report.

We found that a small number of vocational drivers had not notified the licensing authority of their diabetes and were therefore holding licences for which they might not be considered fit. The current position in the United Kingdom, based on the opinion of the secretary of state's honorary medical advisory panel on driving and diabetes mellitus, is that licences for heavy goods or public service vehicles should be revoked or refused for drivers taking insulin who apply for a new licence, existing drivers who become diabetic and require insulin treatment, and diabetic drivers who change from control by diet or oral hypoglycaemic agents, or both, to insulin treatment. Diabetics taking insulin who have been driving for many years, the licence having been granted by the statutory independent licensing authority, in the full knowledge of the condition but against the recommendations of the medical commission on accident prevention, ${ }^{18}$ may be permitted to continue driving provided they meet certain strict medical criteria (minutes of second meeting of the honorary medical advisory panel on driving and diabetes, held at the Royal College of Physicians, London, on 23 February 1988).

We were reassured by the finding that most diabetic drivers stopped driving immediately in the event of hypoglycaemic symptoms and that a similar number carried a permanent supply of glucose or equivalent in their vehicle. These actions are in keeping with the guidelines of the British Diabetic Association. ${ }^{19}$ There is, however, room for improvement, which emphasises the need for careful education at diabetic clinics. This education must include a strong message to patients to declare their condition to both the licensing centre and their insurance company.

This study as with others published recently ${ }^{57}$ depends on the honesty and recall of patients. Many of our patients were prepared to admit to hypoglycaemia while driving and to breaking the law by failing to declare their diabetes to the licensing centre. Others gave sensitive information regarding vocational driving licences. We therefore have no reason to believe that they withheld details on accidents. In the United Kingdom no other adequate means of ascertainment exists. Although all reported accidents are recorded by the police, relating this information to details on individual patients at the licensing centre's medical advisory branch is not possible as medical details are not currently kept on computer. Despite these limitations the available evidence in the United Kingdom is that as a group diabetics treated with insulin have a similar rate of road traffic accidents to the general public. Nevertheless, hypoglycaemia, a disability not usually shared by the general population, has been shown to contribute to accidents. The reason that this problem is not translated into an increased overall accident rate may be that diabetics, being aware of the risk, are more careful drivers. This suggestion is supported by the apparent willingness of diabetics with medical complications to stop driving voluntarily ${ }^{7}$ and the reported reduction in accidents and road traffic offences after the onset of disease..$^{15}$

It remains important to identify those with appreciable disabilities and discourage them from driving. All diabetics must be encouraged to declare their condition to both the driving licence authorities and insurance companies. We recommend that insurance companies should make better use of medical reports before deciding on insurance cover and do not treat diabetic drivers as one uniform high risk group.

We thank Dr E A Rowse, medical adviser to the Secretary of State for Transport, for practical advice and encouragement; Miss Adele Graham and Mr Chris Patterson for helping in design and analysis; and the medical and nursing staff of the clinics, particularly Drs K G Porter, D Burrows, and E A 
Bingham and Sisters Murphy, McKee, and Devlin. Copies of the questionnaire can be obtained from ABS.

1 Waller JA. Chronic medical conditions and traffic safety: review of the California experience. $N$ Engl $\mathcal{F}$ Med 1965;273:1413-20.

Crancer A, McMurray L. Accident and violation rates of Washington's medically restricted drivers. FAMA 1968;205:74-8.

3 Davis TG, Wehling EH, Carpenter RL. Oklahoma's medically restricted drivers. A study of selected medical conditions. Oklahoma State Medical Association fournal 1973;66:322-7.

4 Ysander L. The safety of drivers with chronic disease. $\mathrm{Br}$ f Ind Med 1966;23:28-36.

5 Eadington DW, Frier BM. Type I diabetes and driving experience: an eight year cohort study. Diabetic Med 1989;6:137-41.

6 Cochran WG. Some methods for strengthening the common Chi squared tests. Biometrics 1954;10:417-51.

7 Songer TJ, La Porte RE, Dorman JS, et al. Motor vehicle accidents and IDDM. Diabetes Care 1988;11:701-7.

8 Clarke B, Ward JD, Enoch BA. Hypoglycaemia in insulin-dependent diabetic drivers. BrMed f 1980;281:586.
9 Leyshon GE, Elliott RW, Lyons J, Francis HWS. Diabetics and motorway crashes. Br Med f 1972;ii:405.

10 Lasche EM. The diabetic driver. Diabetes Care 1985;8:189-91.

11 Haunz. EA, Brosseau JD. Non-warning hypoglycemia in drivers with diaunz. EA, Brosseau JD. Non-warning hypo

12 Steel JM. The controversy over insulin-treated diabetics holding a heavy goods vehicle licence. Practical Diabetes 1986;3:202.

13 Grattan E, Jeffcoate GO. Medical factors and road accidents. Br Med $\mathcal{J}$ $1968 ;$; :75-9.

14 Herner B, Smedby B, Ysander L. Sudden illness as a cause of motor vehicle accidents. Br F Ind Med 1966;23:37.

15 Ysander L. Diabetic motor-vehicle drivers without driving-licence restrictions. Acta Chir Scand [Suppl] 1970;409:45-53.

16 Frier BM, Steel JM, Matthews DM, Duncan LJP. Driving and insulindependent diabetes. Lancet 1980; ; $1232-4$.

17 Drasco M, Haggerty CM. A comparison of the British number plates and Snellen vision tests for car driving. Crowthorne: Transport and Road Research vision tests for car driving. Crowthorne: Trans

18 Keen H. Diabetes: (Great Britain, London. Medical aspects of fitness to drive. London: HMSO, 1985. (D.8893958/80 m/9/85.)

19 Day JL. The diabetic handbook: insulin dependent diabetes. London: British Diabetic Association, 1986:134-6.

(Accepted 3 fuly 1989)
Combined Endoscopy Unit, Departments of Medicine and Surgery, Prince of Wales Hospital, Chinese University of Hong Kong, Shatin, NT, Hong Kong

Joseph W C Leung, MRCP, senior lecturer in medicine Sydney S C Chung, FRCSED, senior lecturer in surgery

Correspondence to:

Dr J W C Leung,

Department of Medicine,

Prince of Wales Hospital,

Shatin, NT, Hong Kong.

Br med f 1989;299:595-8

\title{
Electrohydraulic lithotripsy with peroral choledochoscopy
}

\author{
Joseph W C Leung, Sydney S C Chung
}

\begin{abstract}
Objective-To determine the efficacy of peroral electrohydraulic lithotripsy performed with an extra large duodenoscope (outside diameter $14.8 \mathrm{~mm}$ ) and a choledochoscope with a diameter of $4.1 \mathrm{~mm}$ (Olympus "mother and baby" endoscope system) in the removal of very large stones from the common bile duct.
\end{abstract}

Design-Prospective study of patients with giant stones in the common bile duct that were resistant to extraction by conventional means.

Setting-Endoscopy unit at a university hospital.

Patients-Four women and one man aged 48-82 (mean 66.4 years) with a total of nine stones in their common bile ducts ranging from 2.2 to $3.6 \mathrm{~cm}$ in diameter.

Interventions-Peroral electrohydraulic lithotripsy was performed after intravenous sedation and under antibiotic cover. Two endoscopists took part in each procedure, coordination being achieved by means of a video monitor. The procedures were performed with a Lithotron EL-23 lithotripter and a 3 French lithotripsy probe inserted through the choledochoscope under direct vision.

Main outcome measure-Complete clearance of the common bile duct confirmed by occlusion cholangiography.

Results-All nine stones (mean minimal diameter $2.6 \mathrm{~cm}$; mean maximal diameter $3.1 \mathrm{~cm}$ ) were successfully fragmented by electrohydraulic lithotripsy, allowing subsequent extraction with the aid of endoscopy and clearance of the common bile duct. A median of three (range two to five) sessions of endoscopic retrograde cholangiopancreatography were required to achieve complete clearance of the ducts. Patients stayed a median of eight days in hospital after lithotripsy (range eight to 14). There were no complications.

Conclusion-Peroral electrohydraulic lithotripsy offers a safe and effective alternative for the management of patients with large stones in the common bile duct.

\section{Introduction}

The role of endoscopic sphincterotomy in treating patients with stones in the common bile duct is now firmly established. ${ }^{12}$ Ninety per cent of patients with these stones can successfully be treated in this way..$^{34}$ Technical difficulty in extracting stones with the aid of endoscopy increases with their size. Stones more than $2 \mathrm{~cm}$ in diameter are difficult to remove endoscopically.

Several methods have been used to fragment stones in the common duct to facilitate endscopic removal. ${ }^{6}$ Electrohydraulic lithotripsy utilises the principle of high pressure shock waves generated by a high voltage discharge and has been used to fragment urinary stones. ${ }^{7}$ It has been used in the biliary tract through the choledochoscope via a percutaneous transhepatic route $^{8-10}$ or a T tube tract. ${ }^{11}$

We describe our experience with electrohydraulic lithotripsy of stones in the common duct under direct vision using peroral choledochoscopy with the "mother and baby" endoscope system (Olympus Optical, Tokyo).

\section{Patients and methods}

During December 1988 and January 1989 we saw five patients (four women) with giant stones in the common duct in whom stone extraction by conventional methods (including mechanical lithotripsy) had failed. Their mean age was $66 \cdot 4$ years (range 48-82). The reasons for failure were inability to engage a large stone with the basket (three cases) and inability to open the lithotripsy basket in a duct packed with large stones (two). A total of nine large stones were seen in these five patients. The largest diameters ranged from 2.4 to $3.6 \mathrm{~cm}$ (mean $3.1 \mathrm{~cm}$ ) and the smallest diameters from 2.2 to $3.0 \mathrm{~cm}$ (mean $2.6 \mathrm{~cm})$. The sizes of the stones were measured from the radiograph by comparison with the diameter of the endoscope in the same radiograph.

All five patients presented with acute cholangitis. One required emergency nasobiliary drainage in the acute attack. All five patients had their sepsis controlled with antibiotics before attempted stone extraction. Sphincterotomy was performed in four patients, the other patient having had a sphincteroplasty two years previously.

\section{INSTRUMENT}

The Olympus mother and baby endoscope consists of an extra large duodenoscope (mother endoscope, XTJF-5.5) with an external diameter of $14.8 \mathrm{~mm}$. It has a $5 \cdot 5 \mathrm{~mm}$ instrument channel which admits a $4 \cdot 1$ 